\title{
Goals of Treatment Sequencing for Localized Pancreatic Cancer
}

\author{
Douglas B. Evans, MD ${ }^{1}$, Mandana Kamgar, MD, MPH ${ }^{2}$, and Susan Tsai, MD, MHS ${ }^{1}$ \\ ${ }^{1}$ Pancreatic Cancer Program, Department of Surgery, The Medical College of Wisconsin, Milwaukee, WI; ${ }^{2}$ Pancreatic \\ Cancer Program, Department of Medicine, The Medical College of Wisconsin, Milwaukee, WI
}

There is now general consensus that pancreatic cancer is a systemic disease at the time of diagnosis, even among patients with apparent localized disease. ${ }^{1}$ This clinical observation was in fact appreciated many decades ago, when it became apparent that the vast majority of patients operated upon with curative intent experienced metachronous recurrence even when the operation went "perfectly." However, despite improved clarity around the natural history of pancreatic adenocarcinoma, there remains debate on optimal treatment sequencing. The manuscript by Altman and colleagues in this issue of Annals of Surgical Oncology adds to the now robust body of literature demonstrating that patients who undergo surgery (first) for operable pancreatic cancer may never receive intended adjuvant therapy. ${ }^{2}$ If this is true, what is preventing the more widespread use of systemic therapy first for this disease?

\section{IS THERE ANYTHING TO BE LEARNED FROM HISTORY?}

Because the operation of pancreaticoduodenectomy (Whipple procedure) was (and remains) of significant magnitude and because many patients who successfully underwent this operation recurred even within 1 year of surgery, treatment sequencing other than immediate surgery was an obvious oncologic alternative. ${ }^{3}$ Initial clinical trials of neoadjuvant therapy were developed in an effort to both: identify those patients with rapidly progressive

(C) Society of Surgical Oncology 2019

First Received: 7 August 2019;

Published Online: 6 September 2019

D. B. Evans, MD

e-mail: devans@mcw.edu disease at the time of posttreatment re-staging evaluation (prior to surgery) and thereby avoid such a large operation which would be of no oncologic benefit; and, to better define (select) those patients who may live long enough to benefit from a large operation as they were felt to be the ones most likely to have stable or responding disease after the receipt of systemic therapy, chemoradiation, or both. ${ }^{3-8}$ However, there was considerable criticism of treatment sequencing other than a surgery-first approach, especially from those institutions involved in the study of adjuvant therapy. It is true that neoadjuvant treatment sequencing was developed before we had systemic therapies as effective as exist today but, investigators pursued this approach in an effort to better select patients to go and NOT to go to the operating room as well as to develop the infrastructure needed to deliver systemic therapy and chemoradiation to patients of advanced age who often had biliary obstruction. In fact, the lack of such infrastructure, resulting in the inability to consistently deliver neoadjuvant therapy to newly diagnosed patients with localized pancreatic cancer, may represent the major obstacle to neoadjuvant treatment sequencing. ${ }^{9}$ As therapies improved, the survival duration of operated patients became much longer, eventually generating a greater level of enthusiasm for a trip to the infusion center rather than the operating room as initial treatment of localized, operable pancreatic cancer. ${ }^{10-12}$ It is important to remember that the initial attempts at neoadjuvant treatment sequencing were developed in an effort to advocate for those patients who were at highest risk for early postoperative failure (by detecting disease progression at the time of preoperative re-staging and avoiding surgery); an argument which proved to be largely unsuccessful in swaying opinion against immediate surgery. Enthusiasm for neoadjuvant therapy did not gain momentum until the survival durations of those patients who successfully completed all neoadjuvant therapy and surgery began to increase-consistent with the incorporation 
of more effective systemic therapy and chemoradiation. ${ }^{10-12}$ However, those institutions which have not solved the challenges of patient management (biliary decompression [routine use of metal stents], supportive care, diabetes management, hydration, etc.) have struggled to adapt to anything other than a surgery-first approach.

\section{IN A FIELD WHERE INTENT TO TREAT IS SO HIGHLY VALUED, WHY IS DARWINIAN SELECTION SO ADMIRED?}

The manuscript by Altman and colleagues in this issue of Annals of Surgical Oncology highlights the fact that only a minority of patients who undergo successful surgery for localized pancreatic cancer receive intended adjuvant therapy this was true even for the time period of 2009-2014 by which time multimodality therapy was well accepted for this disease. The obvious concern is that as systemic therapies become even more effective, they will never reach the patient if a surgery-first approach is taken. Despite advances in surgery and perioperative management, challenges with postoperative recovery, due to the magnitude of the operation which often is performed in patients of advanced age, may be hard to overcome. As discussed in the Altman manuscript, perioperative results may be improved by the concentration of pancreatic surgery in higher-volume centers; however, there is increasing pressure placed on employed physicians to keep patients within their health system/network regardless of diseasesite expertise. ${ }^{13}$

Importantly, a neoadjuvant approach includes all patients at the time of diagnosis-assuming they have a performance status acceptable for anticancer therapy (as opposed to best supportive care) and a CT/MRI which reveals a resectable or borderline resectable primary pancreatic cancer. This reflects the real-world experience in managing patients who often demonstrate a wide spectrum of comorbidities and family support and usually require durable biliary decompression. In sharp contrast is the case with clinical trials of adjuvant therapy which include only patients who: are found not to have metastatic disease at the time of planned pancreatectomy (80-90\% of the total if preoperative imaging is well done); survive surgery and recover in a timely fashion and are agreeable to further treatment; have no evidence of early disease progression on postsurgical re-staging evaluation; and pass the assessment of the medical oncologist-which is becoming more difficult as adjuvant therapy with FOLFIRINOX may have raised the bar of patient performance status due to the anticipated toxicities of therapy. Indeed, the results of the recently reported Unicancer-GI-PRODIGE trial of adjuvant modified FOLFIRINOX (mFOLFIRINOX) versus gemcitabine reflect a Darwinian selection bias that may make the study results impossible to adapt to the clinical practice of the average oncologist. ${ }^{14}$ The results of this trial likely apply only to the fittest XX\% (could be X\% if one considers only the Medicare population in the SEER registry?) of all patients who are brought to the operating room for planned surgical resection of their pancreatic cancer immediately after diagnosis - the true denominator if an intent-to-treat analysis were performed. Pancreatic cancer may be somewhat unique within solid tumor oncology in the complexity of the operative gastrointestinal reconstruction which predisposes to a more prolonged recovery especially in patients of advanced age with some degree of medical comorbidity.

Undoubtedly there are some patients with operable pancreatic cancer who likely cannot tolerate multiple treatments in series, although they may be hard to identify as distinct from others at the time of diagnosis. For this subset of patients, is surgery better than no surgery at all, which could happen if the toxicities of neoadjuvant therapy make surgery no longer an option? Available evidence would suggest not. ${ }^{1,2,15}$ Surgery, as a "Hail Mary pass" for this disease, almost never works. Darwinian selection should be used in the treatment sequencing of operable pancreatic cancer; it should be used to help determine which patients are most likely to benefit from surgery (while maintaining careful record of all patients who initiated treatment with curative intent)-NOT after the operation has been done in an effort to determine which patients will benefit from adjuvant therapy. Chemotherapy and radiation can both be turned off if the treatment appears to be worse than the disease for a given patient. We do not have the ability to do this with surgery; once the decision has been made, anesthesia induced and the operation completed, the mortality/morbidity of pancreatic surgery has been conveyed to the patient in its entirety. Reports of surgery-first or surgery-last which fail to report the denominator of all patients (recorded at the time of diagnosis after high-quality cross-sectional imaging [staging]) by intention to treat contain an inherent selection bias which renders such data uninterpretable to a more generalized population. ${ }^{14,16}$

\section{WHAT SHOULD WE DO?}

Patients with newly diagnosed pancreatic cancer should be accurately staged. An objective CT-based system for radiographic staging allows one to apply stage specific therapy to all patients who have a performance status and medical condition acceptable for anticancer therapy (Table 1). Durable biliary decompression is combined with optimal blood sugar control, diet and nutritional counseling 
TABLE 1 Classification of resectable, borderline resectable and locally advanced pancreatic adenocarcinoma based on objective tumor-vessel relationships seen on high quality cross-sectional imaging (CT/MRI). Modified from Ref. ${ }^{17}$

\begin{tabular}{|c|c|c|c|c|c|}
\hline \multirow{2}{*}{\multicolumn{2}{|c|}{$\begin{array}{l}\text { Vascular structures which } \\
\text { determine the stage of disease for } \\
\text { localized pancreatic cancer }\end{array}$}} & \multirow{3}{*}{$\begin{array}{l}\text { Resectable } \\
\text { No radiographic } \\
\text { evidence of } \\
\text { abutment or } \\
\text { encasement }\end{array}$} & \multirow{3}{*}{$\begin{array}{l}\text { Borderline Resectable } \\
\leq 180^{\circ} \text { (abutment) }\end{array}$} & \multicolumn{2}{|l|}{ Locally Advanced } \\
\hline & & & & \multirow{2}{*}{$\begin{array}{l}\text { Type A } \\
\begin{array}{l}>180^{\circ} \text { (encasement) but } \\
\leq 270^{\circ}\end{array}\end{array}$} & \multirow{2}{*}{$\begin{array}{l}\text { Type B } \\
>270^{\circ} \text { encasement }\end{array}$} \\
\hline $\begin{array}{l}\text { Tumor- } \\
\text { artery } \\
\text { anatomy }\end{array}$ & $\begin{array}{l}\text { SMA (usually } \\
\text { pertains to a } \\
\text { tumor of the head } \\
\text { or uncinate } \\
\text { process) }\end{array}$ & & & & \\
\hline & $\begin{array}{l}\text { Celiac artery } \\
\text { (usually pertains } \\
\text { to a tumor of the } \\
\text { pancreatic body) }\end{array}$ & $\begin{array}{l}\text { No radiographic } \\
\text { evidence of } \\
\text { abutment or } \\
\text { encasement }\end{array}$ & $\leq 180^{\circ}$ (abutment) & $\begin{array}{l}>180^{\circ} \text { (encasement) but does } \\
\text { not extend to the aorta and } \\
\text { amenable to celiac resection } \\
\text { (with or without } \\
\text { reconstruction) }\end{array}$ & $\begin{array}{l}>180^{\circ} \text { and abutment/ } \\
\text { encasement of the aorta }\end{array}$ \\
\hline & $\begin{array}{l}\text { Hepatic artery } \\
\text { (HA) (usually } \\
\text { pertains to a } \\
\text { tumor of the } \\
\text { pancreatic } \\
\text { neck/head) }\end{array}$ & $\begin{array}{l}\text { No radiographic } \\
\text { evidence of } \\
\text { abutment or } \\
\text { encasement }\end{array}$ & $\begin{array}{l}\text { Short segment } \\
\text { abutment/encasement } \\
\text { without extension to } \\
\text { celiac artery or HA } \\
\text { bifurcation }\end{array}$ & $\begin{array}{l}>180^{\circ} \text { encasement with } \\
\text { extension to celiac artery and } \\
\text { amenable to vascular } \\
\text { reconstruction }\end{array}$ & $\begin{array}{l}>180^{\circ} \text { encasement with } \\
\text { extension beyond } \\
\text { bifurcation of proper } \\
\text { HA into right and left } \\
\text { hepatic arteries }\end{array}$ \\
\hline $\begin{array}{l}\text { Tumor- } \\
\quad \text { vein } \\
\text { anatomy }\end{array}$ & $S M V-P V$ & $\begin{aligned} \leq & 50 \% \text { narrowing } \\
& \text { of SMV, PV } \\
& \text { SMV-PV }\end{aligned}$ & $\begin{array}{l}\text { 50\% narrowing of } \\
\text { SMV, PV, SMV-PV } \\
\text { with a distal and } \\
\text { proximal target for } \\
\text { reconstruction }\end{array}$ & $\begin{array}{l}\text { Occlusion without obvious } \\
\text { option for reconstruction or at } \\
\text { least a marginal proximal or } \\
\text { distal target for venous } \\
\text { reconstruction }\end{array}$ & \\
\hline \multicolumn{2}{|c|}{$\begin{array}{l}\text { Traditionally } \\
\text { considered } \\
\text { for resection } \\
\text { after } \\
\text { neoadjuvant } \\
\text { therapy }\end{array}$} & Yes & Yes & No & No \\
\hline
\end{tabular}

$S M A$ superior mesenteric artery, $S M V$ superior mesenteric vein, $P V$ portal vein, $S M V-P V$ superior mesenteric-portal vein

TABLE 2 The importance of pre-treatment staging for the development of goals of therapy; specifically, the likelihood of completing all planned neoadjuvant therapy and surgical resection of the primary pancreatic cancer

\begin{tabular}{ll}
\hline Stage of disease & $\begin{array}{l}\text { Potential for completion of all intended } \\
\text { neoadjuvant therapy and surgery (\%) }\end{array}$ \\
\hline Resectable & 90 \\
Borderline Resectable & 75 \\
Locally Advanced A & 60 \\
Locally Advanced B & 25 \\
\hline
\end{tabular}

Data generated from the following manuscripts: Refs. ${ }^{10,12,18,19}$

and psychological support within the framework of a multidisciplinary program. If available, genetic counseling is also included and when not available, genetic testing can still be performed if the patient is willing to pay for this service. Hopefully this all leads to enrollment in a clinical trial. When a clinical trial is not available, we would recommend neoadjuvant therapy for all stages of non- metastatic pancreatic cancer. With the use of accurate staging, we can provide the patient and his/her family the likelihood of completing all intended neoadjuvant therapy and surgery (Table 2). For patients who are unable to travel, have limited social and family support, or have medical comorbidities that make multiple treatments in series likely impossible, goals of therapy need to be redefined. Not everyone is a candidate for 4 months of chemotherapy, radiation/chemoradiation and surgery. For those who begin neoadjuvant therapy (mFOLFIRINOX and gemcitabine doublets/triplets are becoming the standard outside of a clinical trial), re-staging should be performed after 2 months of therapy and in general, they are treated as outlined in Table 3 and Fig. 1. The delivery of potentially curative neoadjuvant therapy requires, at a minimum: dedicated medical, radiation and surgical oncologists, talented radiologists, experienced interventional gastroenterologists and cytopathologists, and a team of support personnel (advanced practice providers, dieticians, diabetes specialists and psychologists). Herein lies the 
TABLE 3 General treatment guidelines for the management of resectable and borderline resectable pancreatic cancer (operable disease) as well as locally advanced disease (Type A and B) outside of a clinical trial-all patients receive initial systemic therapy with restaging after the first 2 months of treatment

\begin{tabular}{|c|c|c|}
\hline Stage of disease & $\begin{array}{l}\text { Re-staging after } 2 \text { months of systemic } \\
\text { therapy }\end{array}$ & Re-staging after 4 months of systemic therapy \\
\hline Resectable & $\begin{array}{l}\text { Response }^{\mathrm{a}} \text { : additional } 2 \text { months of same } \\
\text { systemic therapy } \\
\text { Lack of response or local progression }{ }^{\mathrm{b}} \text { : } \\
\text { transition to radiation/chemoradiation }\end{array}$ & $\begin{array}{l}\text { Stable or Responding disease after } 4 \text { months of systemic therapy: transition to } \\
\text { radiation/chemoradiation with preoperative intent }\end{array}$ \\
\hline $\begin{array}{l}\text { Borderline } \\
\text { Resectable }\end{array}$ & 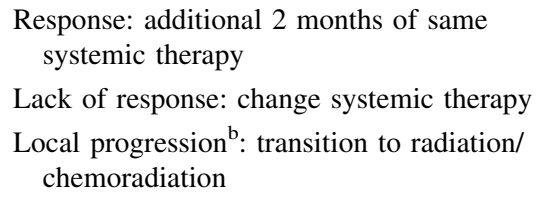 & $\begin{array}{l}\text { Stable or Responding disease after } 4 \text { months of systemic therapy: transition to } \\
\text { radiation/chemoradiation with preoperative intent }\end{array}$ \\
\hline $\begin{array}{l}\text { Locally } \\
\text { Advanced (A } \\
\text { and B) }\end{array}$ & $\begin{array}{l}\text { Response: additional } 2 \text { months of same } \\
\text { systemic therapy } \\
\text { Lack of response or local progression: } \\
\text { change systemic therapy }\end{array}$ & $\begin{array}{l}\text { Stable or Responding disease after } 4-6 \text { months of systemic therapy: transition } \\
\text { to radiation/chemoradiation with either preoperative intent if surgery deemed } \\
\text { possible, or consider ablative chemoradiation (dose escalation) if surgery } \\
\text { deemed not possible }\end{array}$ \\
\hline
\end{tabular}

Table assumes that those with distant disease progression receive second line therapy or an appropriate clinical trial

${ }^{a}$ Response based on clinical evaluation, radiology findings and laboratory biomarker levels

${ }^{b}$ For patients who receive $<4$ months of systemic therapy prior to chemoradiation and surgery, postoperative adjuvant therapy is offered if node positive disease is found on final pathology ${ }^{20}$

${ }^{\mathrm{c}} \mathrm{A}$ decision for or against surgery is always made before embarking on radiation/chemoradiation; if surgery is not possible, ablative radiation therapy (dose escalation) is considered

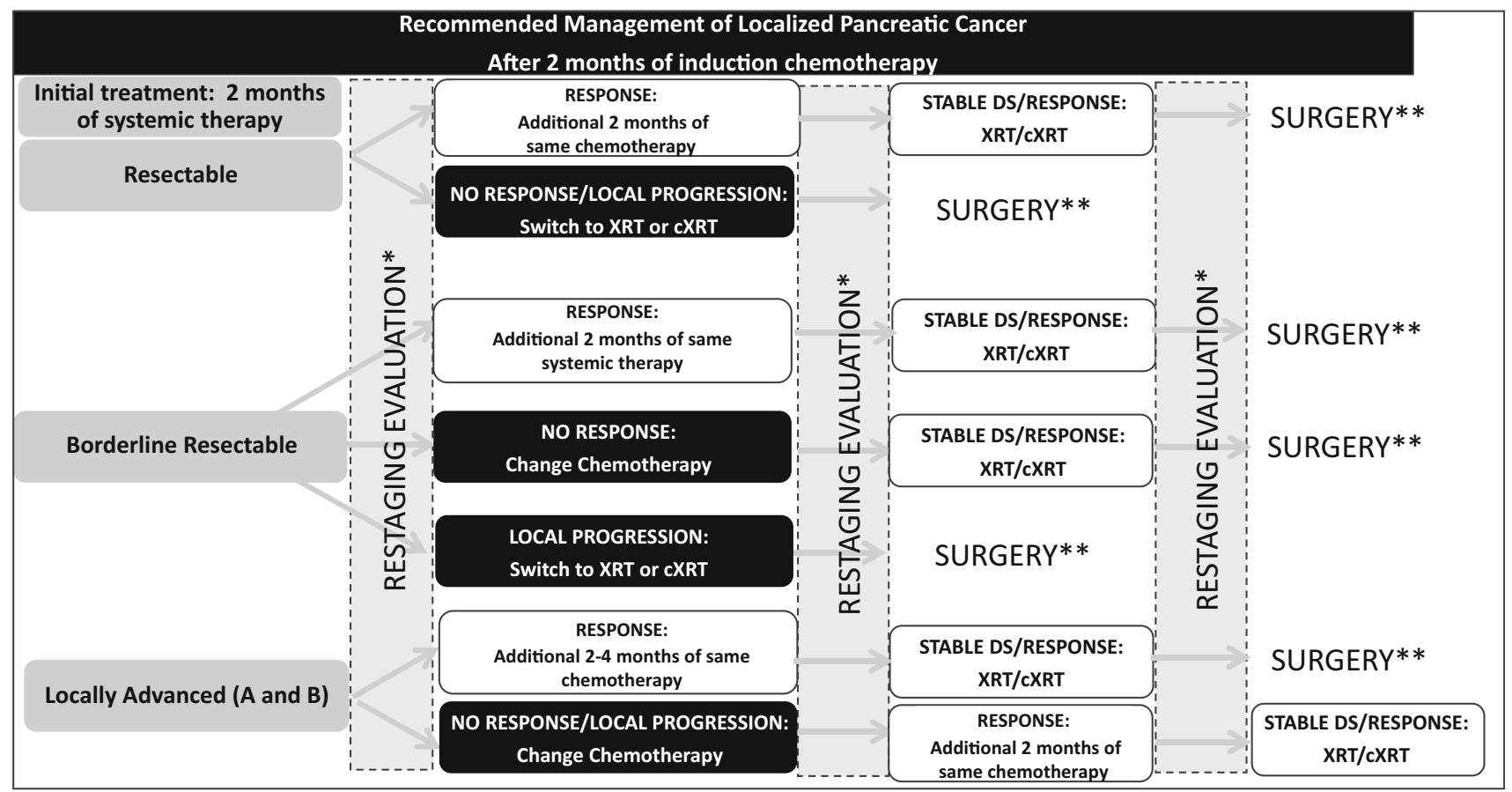

*Restaging evaluation based on: clinical assessment, radiologic findings, laboratory biomarkers.

**Restaging evaluation always also completed prior to surgery. Objective CT criteria are used to determine local tumor resectability - which does NOT change in the absence of disease progression.

FIG. 1 Schematic outline of the information contained in Table 3 illustrating treatment guidelines for the management of nonmetastatic Pancreatic Cancer outside of a Clinical Trial-as in Table 3, we assume that those with distant disease progression receive second line therapy or an appropriate clinical trial 
challenge and probably the reason for the lack of more widespread application of neoadjuvant therapy to a disease where it seems to make so much sense. Surgery first is an easier paradigm to complete for the medical team as no one is responsible for those patients who drop out along the way. Importantly, the survival results of those who pass the test of Darwinian selection and successfully receive adjuvant therapy cannot be extrapolated to the patient at the time of diagnosis; no one really knows if they will ever receive adjuvant therapy. The data contained in the Altman manuscript suggests that their chances are very low. The use of surgery-first for operable pancreatic cancer appears to be a dead-end street at least for those aged 66 or older who are in the SEER database. The failure of treatment guidelines to recognize this (in resectable disease) reflects the challenge of achieving consensus among experts who may not realize that the inability to deliver adjuvant therapy is stage agnostic - and more dependent on the operation performed and the age and medical condition of the patient. Risking the ability to deliver systemic therapy to patients with resectable pancreatic cancer, by embarking on a surgeryfirst approach, may negatively impact the survival of those patients most likely to benefit from multimodality therapy.

\section{REFERENCES}

1. Wolff RA, Crane CH, Li D, Evans DB, Maitra A, Tsai S. Neoplasms of the exocrine pancreas. In: Bast RC, Croce CM, Hait WN, Hong WK, Kufe DW, Piccart-Gebhart M, Pollock RE, Weichelbaum RR, Wang, H, Holland JF, Frei E (eds) Holland-Frei Cancer Medicine, 9th edn. Hoboken: Wiley Blackwell; 2017:1129-50.

2. Altman AM, Wirth K, Marmor S, Lou E, Chang K, Hui JYC, Tuttle TM, Jensen EH, Denbo JW. Completion of adjuvant chemotherapy following upfront surgical resection for pancreatic cancer is uncommon yet associated with improved survival. Ann Surg Oncol. 2019. https://doi.org/10.1245/s10434-019-07602-6.

3. Evans DB, Rich TA, Byrd DR, Cleary KR, Connelly JH, Levin B, Charnsangavej C, Fenoglio CJ, Ames FC. Preoperative chemoradiation and pancreaticoduodenectomy for adenocarcinoma of the pancreas. Arch Surg. 1992;127:1335-9.

4. Spitz FR, Abbruzzese JL, Lee JE, Pisters PWT, Lowy AM, Fenoglio CJ, Cleary KR, Janjan NA, Goswitz MS, Rich TA, Evans DB. Preoperative and postoperative chemoradiation strategies in patients treated with pancreaticoduodenectomy for adenocarcinoma of the pancreas. J Clin Oncol. 1997;15:928-37.

5. Pisters PWT, Abbruzzese JL, Janjan NA, Cleary KR, Charnsangavej C, Goswitz MS, Rich TA, Raijman I, Wolff RA, Lenzi R, Lee JE, Evans DB. Rapid-fractionation preoperative chemoradiation, pancreaticoduodenectomy, and intraoperative radiation therapy for resectable pancreatic adenocarcinoma. J Clin Oncol. 1998;16:3843-50.

6. Pisters PWT, Wolff RA, Janjan NA, Cleary KR, Charnsangavej C, Crane C, Lenzi R, Vauthey JN, Lee JE, Abbruzzese JL, Evans DB. Preoperative paclitaxel and concurrent rapid-fractionation radiation for resectable pancreatic adenocarcinoma: toxicities, histologic response rates, and event-free outcome. J Clin Oncol. 2002;20:2537-44.

7. Evans DB, Varadhachary GR, Crane CH, Sun CC, Lee JE, Pisters PWT, Vauthey JN, Wang H, Cleary KR, Staerkel GA,
Charnsangavej C, Lano EA, Ho L, Lenzi R, Abbruzzese JL, Wolff RA. Preoperative gemcitabine-based chemoradiation for patients with resectable adenocarcinoma of the pancreatic head. $J$ Clin Oncol. 2008;26(21):3496-502.

8. Varadhachary GR, Wolff RA, Crane CH, Sun CC, Lee JE, Pisters PWT, Vauthey JN, Abdalla E, Wang H, Staerkel GA, Lee JH, Ross WA, Tamm EP, Bhosale PR, Balachandran A, Krishnan S, Das P, Abbruzzese JL, Evans DB. Preoperative gemcitabine and cisplatin followed by gemcitabine-based chemoradiation for resectable adenocarcinoma of the pancreatic head. J Clin Oncol. 2008;26(21):3487-95.

9. Fathi A, Christians KK, George B, Ritch PS, Erickson BA, Tolat P, Johnston FM, Evans DB, Tsai S. Neoadjuvant therapy for localized pancreatic cancer: guiding principles. J Gastrointest Oncol. 2015;6(4):418-29.

10. Christians KK, Heimler JW, George B, Ritch PS, Erickson BA, Johnston F, Tolat PP, Foley WD, Evans DB, Tsai S. Survival of patients with resectable pancreatic cancer who received neoadjuvant therapy. Surgery. 2016;159(3):893-900.

11. Christians KK, Tsai S, Mahmoud A, Ritch P, Thomas JP, Wiebe L, Kelly T, Erickson B, Wang H, Evans DB, George B. Neoadjuvant FOLFIRINOX for borderline resectable pancreas cancer: a new treatment paradigm? Oncologist. 2014;19(3):266-74.

12. Tsai S, Christians KK, George B, Ritch PS, Dua K, Khan A, Mackinnon AC, Tolat P, Ahmad SA, Hall WA, Erickson BA, Evans DB. A phase II clinical trial of molecular profiled neoadjuvant therapy for localized pancreatic ductal adenocarcinoma. Ann Surg. 2018;268(4):610-9.

13. Evans DB, Tsai S. Volume-outcome in cancer surgery: why has the data not affected policy change? Ann Surg Oncol. 2014;21(13): 4056-8.

14. Conroy T, Hammel P, Hebbar M, Ben Abdelghani M, Wei AC, Raoul JL, et al. FOLFIRINOX or gemcitabine as adjuvant therapy for pancreatic cancer. $N$ Engl J Med. 2018;379(25): 2395-406.

15. Tsai S, Evans DB. Neoadjuvant and adjuvant therapy for localized pancreatic cancer. In Cameron JL, Cameron AM (eds) Current surgical therapy, 12th edn. Philadelphia: Elsevier; 2017:559-64.

16. Truty MJ, Kendrick ML, Nagorney DM, Smoot RL, Cleary SP, Graham RP, et al. Factors predicting response, perioperative outcomes, and survival following total neoadjuvant therapy for borderline/locally advanced pancreatic cancer. Ann Surg. 2019. h ttps://doi.org/10.1097/SLA.0000000000003284.

17. Evans DB, George B, Tsai S. Non-metastatic pancreatic cancer: resectable, borderline resectable, and locally advanced-definitions of increasing importance for the optimal delivery of multimodality therapy. Ann Surg Oncol. 2015:22(11):3409-13.

18. Barnes CA, Chavez MI, Tsai S, Aldakkak M, George B, Ritch PS, Dua K, Clarke CN, Tolat P, Hagen C, Hall WA, Erickson BA, Evans DB, Christians KK. Survival of patients with borderline resectable pancreatic cancer who received neoadjuvant therapy and surgery. Surgery. 2019;166(3):277-85.

19. Chatzizacharias NA, Tsai S, Griffin M, Tolat P, Ritch P, George B, Barnes C, Aldakkak M, Khan AH, Hall W, Erickson B, Evans DB, Christians KK. Locally advanced pancreas cancer: staging and goals of therapy. Surgery. 2018;163(5):1053-62.

20. Barnes CA, Krepline AN, Aldakkak M, Clarke CN, Christians KK, Khan AH, Hunt BC, Ritch PS, George B, Hall WA, Erickson BA, Evans DB, Tsai S. Is adjuvant therapy necessary for all patients with localized pancreatic cancer who have received neoadjuvant therapy? J Gastrointest Surg. 2017;21(11):1793-803.

Publisher's Note Springer Nature remains neutral with regard to jurisdictional claims in published maps and institutional affiliations. 